\title{
Considerações Sobre o Puro Conhecimento em Arthur Schopenhauer
}

Sara Pereira Dias

\section{Resumo:}

Segundo Schopenhauer, a tentativa de Kant em fazer da metafísica uma ciência não só limitou o conhecimento do indivíduo como também instaurou um negativismo em torno da metafísica. Assim, a solução para salvaguardar a metafísica e o sujeito cognoscente estaria no conhecimento da Coisa-Em-Si. Este conhecimento se mostra possível no pensamento schopenhaueriano por meio da contemplação desinteressada de objetos, pois tal contemplação levaria o sujeito a contemplar não o objeto, mas a Ideia platônica, que é a Coisa-EmSi na forma mais geral da representação. Esta contemplação é fundamentada na intuição e é concebida pelo flósofo como o conhecimento mais puro e perfeito da essência do mundo.

Palavras-chave: Metafísica - Intuição - Ideia platônica - Contemplação Conhecimento. 
A metafísica do belo schopenhaueriana pode ser entendida como uma crítica às ciências em função do seu método de abordar os objetos que, segundo o filósofo, nunca chega ao que há de essencial neles após vários estudos de causa e efeito. As ciências só conseguem dizer algo sobre algum objeto a partir do momento em que ele é abordado segundo alguma das formas do princípio de razão, ou seja, um objeto para ser visto e conhecido deve estar em um determinado lugar, em um dado instante, sob determinadas circunstâncias. Somente sob essas considerações as ciências podem obter certo conhecimento acerca de um objeto qualquer. ${ }^{\mathrm{I}}$

Em consequência do fio condutor do princípio de razão utilizado pelas ciências, a essência ou Coisa-Em-Si do mundo nunca é encontrada, pois quando não se tem mais uma explicação para os acontecimentos de causa e efeito da realidade empírica a ciência esbarra nas forças naturais. As forças naturais são forças como gravidade, coesão, impenetrabilidade entre outras; tais forças são completamente obscuras e não dão a resposta ao que seria a essência íntima de cada ser. Assim, estas forças se apresentam como obstáculo à ciência, devido ao fato de seguir a via do princípio de razão, princípio de explicação do fenômeno, que não dá acesso à Coisa-Em-Si. Ora, podemos pensar que foi justamente o que Kant expressou na Crítica da Razão Pura, "não podemos conhecer objeto algum como coisa-em-si, mas somente enquanto objeto da intuição sensível, isto é, como fenômeno” (Kant, 2005, p. 34). Para Schopenhauer, é exatamente aí que se encontra a limitação da ciência e, conseguintemente, da filosofia de Kant, pois a questão apresentada pelo filósofo é que por trás do fenômeno existe algo que pode ser conhecido.

A única forma pela qual isto poderia acontecer é, primeiramente, a CoisaEm-Si se objetivar, isto é, a Vontade tem que se tornar objeto de conhecimento para o puro sujeito. Segundo Schopenhauer, a visibilidade da Coisa-Em-Si é instituída pelas Ideias platônicas, graus imediatos e adequados da Vontade. Esta denominação, Ideias platônicas, deve-se ao fato de que, segundo o filósofo,

Reconhecemos nesses graus as Ideias de Platão, na medida em que são justamente espécies determinadas, ou formas e propriedades originárias e imutáveis dos corpos orgânicos e inorgânicos, bem como das forças naturais que se manifestam segundo leis da natureza (SCHOPENHAUER, 2005, p. 235).

As Ideias são protótipos de inúmeros fenômenos, dentre eles o próprio indivíduo. A distinção destes dois elementos de conhecimento, Ideias e

I A ciência é falha e insatisfatória com relação à metafísica, uma vez que ela não alcança a essência mais íntima dos seres. 
fenômenos, reside no fato de que as Ideias, além de serem a forma original de todo fenômeno, não estão submetidas em nenhum momento às três formas do princípio de razão - tempo, espaço e causalidade. Elas resistem à pluralidade, à mudança e à finitude, características estas inerentes aos fenômenos.

Seguindo a doutrina de Platão, Schopenhauer observa que as Ideias são a única fonte de um conhecimento propriamente dito verdadeiro e puro, "pois o objeto de um verdadeiro conhecimento só pode ser o que sempre é, em qualquer consideração (logo, em si mesmo), não o que é de novo também não é, dependendo de como se o vê" (ibidem, p. 238). Ainda que o mundo imanente seja fonte de conhecimento, tal conhecimento não é seguro o suficiente para que o indivíduo confie nele, pois o que se apresenta ao indivíduo não passa de uma ilusão.

O princípio de razão é o elemento principal desenvolvido pelo indivíduo ${ }^{2}$ para o conhecimento do mundo. Então, podemos deduzir que é impossível ao indivíduo conhecer as Ideias platônicas, visto que elas fogem às regras de conhecimento pertencentes ao indivíduo. Como pode Schopenhauer falar tanto delas se é impossível conhecê-las? Realmente, conhecer as Ideias pelo princípio de razão é algo totalmente impossível, uma vez que tudo o que acontece no mundo ou ao objeto é justificado pelo princípio de explicação do fenômeno não do metafísico. Mas,

(...) Se, numa suposição absurda, fosse-nos permitido não mais conhecer coisas particulares, nem acontecimentos, nem mudanças, nem pluralidade, mas apenas Ideias, apenas o escalonamento das objetivações de uma única e mesma Vontade, verdadeira coisa-em-si, apreendidas em puro e límpido conhecimento; se, como sujeito do conhecer, não fossemos ao mesmo tempo indivíduos, ou seja, se nossa intuição não fosse intermediada por um corpo, de cujas afecções ela parte, corpo que é apenas querer concreto, objetidade da Vontade, portanto objeto entre objetos, e que, enquanto tal, só pode aparecer na consciência pelas formas do princípio de razão (...) então o nosso mundo seria um Nunc stans - presente contínuo (ibidem, p. 243).

É preciso encontrar outra via de conhecimento além daquela fornecida pelo princípio de razão. E qual seria esta via, já que somente pelo princípio de razão o indivíduo consegue determinar o que lhe aparece?

$2 \mathrm{Na}$ verdade, todo mecanismo de conhecimento inerente ao indivíduo é um artífice desenvolvido pela Vontade para manipular os indivíduos. Com efeito, se todo o conhecimento do indivíduo provém do uso de sua razão, que, por sua vez, é apenas uma objetivação da Vontade, portanto, todo o conhecimento em geral tem como função servir a Vontade. Para mais detalhes, ler O mundo como vontade e como representação, Livro III, \$ 33, edição de 2005 . 
Segundo o filósofo da Vontade, existe um modo pelo qual a unidade indissolúvel do fenômeno pode ser conhecida. A Ideia platônica, antes de tudo, é objeto, visto que é a Coisa-Em-Si enquanto objetidade. Se a Ideia é objeto, então, abre-se a possibilidade de se pensar outra via para o verdadeiro conhecimento, porque a Ideia preserva "a forma primeira e mais universal (...) da representação em geral, a do ser-objeto para um sujeito" (ibidem, p. 242). Para que o indivíduo conheça a Ideia, exige-se que ocorra "uma mudança prévia no sujeito (correspondente e análoga àquela grande mudança na natureza inteira do objeto) em virtude da qual o sujeito, na medida em que conhece a Ideia, não é mais indivíduo" (ibidem, p. 243). Em outras palavras, para que o conhecimento da Ideia se torne possível, é necessário que o sujeito deixe de ser indivíduo e transforme-se em puro sujeito do conhecimento. ${ }^{3}$ Este, em oposição ao simples sujeito ou sujeito comum, é destituído de vontade e seu modo de conhecer não está em relação com objetos submetidos ao princípio de razão, o conhecimento do objeto, neste caso, é adquirido pela contemplação.

Quando o sujeito deixa de considerar as coisas como indivíduo, isto é, abandonando o princípio de razão, a admiração do sujeito pelo objeto não está mais conectada a um ato racional. São desconsiderados no objeto "o Onde, o Quando, o Por que e o Para Quê" (ibidem, p. 246), condições intimamente ligados ao princípio de razão. Imediatamente sai de cena o princípio de razão e entra a intuição como preenchimento de toda a consciência do sujeito. A respeito de como a intuição incide sobre a transformação do sujeito, escreve o filósofo:

os conceitos da razão não mais ocupam a consciência mas, em vez disso, todo o poder do espírito é devotado à intuição e nos afunda por completo nesta (...) a gente se PERDE por completo nesse objeto, isto é, esquece o próprio indivíduo, o próprio querer, e permanece apenas como claro espelho do objeto (ibidem, p. 246).

$\mathrm{Na}$ intuição pura não há uso do princípio de razão. "A intuição pura, também chamada 'estética', arrasta-nos para além do mundo fenomênico, isto é, para fora da consciência normal, ainda que permaneçamos sempre, de algum modo, amarrados a esta" (MAIA, I99I, p. I42). Portanto, é afastando-se do

3 É necessário destacar a diferença que existe entre sujeito do conhecimento e puro sujeito do conhecimento. O primeiro é o homem comum ou indivíduo, aquele que só conhece um objeto condicionando-o ao princípio de razão e às suas necessidades pessoais; o segundo, por sua vez, não condiciona os objetos ao princípio de razão e nem com suas necessidades. Por conseguinte, o intelecto do puro sujeito do conhecimento se vê livre da vontade; isto é, o nível intelectual é maior do que o desejo ou necessidade provocado pela vontade individual. 
princípio de razão que se chega à verdade. A intuição da Ideia se dá no próprio mundo, pois tanto a natureza quanto a obra de arte são alguns dos elementos apresentados pelo filósofo para o conhecimento da objetidade mais próxima da Coisa-Em-Si.

Para tanto, é necessário repensar o conceito intuição. Este deriva do latim, Intuitus, e significa: ver em, contemplar, sendo sua definição no dicionário de filosofia, a saber : "Relação direta (sem intermediários) com um objeto qualquer; por isso, implica a presença efetiva do objeto" (ABBGANANO, 2007, p. 58I).

Esta definição é extremamente significativa na teoria metafísica da arte de Schopenhauer, uma vez que a objetidade mais adequada da Coisa-Em-Si só é conhecida por meio da contemplação desinteressada do belo. Assim, "Intuir" significa "ver" sem obstáculos àquilo que se anuncia aos sentidos por meio da contemplação do belo. Este se faz presente em objetos representados em obra de arte ou efetivados na natureza.

No momento da contemplação, o objeto que se coloca imediatamente na presença do sujeito não é mais um objeto fenomênico, objetivação da objetidade, mas a Ideia - objetidade da própria Coisa-Em-Si. O fato aqui é que, no momento da contemplação estética da Ideia, instala-se na consciência do indivíduo outra forma de vivência do cotidiano, há um distanciamento daquele conhecimento utilizado pelo princípio de razão e o indivíduo encontra na contemplação do objeto o verdadeiro conhecimento. Desse modo, o que o sujeito conhece não é mais um objeto temporal, mas a objetidade adequada da Vontade, deixando o sujeito de ser indivíduo para ser o atemporal PURO SUJEITO DO CONHEGIMENTO destituído de vontade e sofrimento (SCHOPENHAUER, 2005, p. 246). O puro sujeito, em pleno estado de contemplação, é arrebatado pela Ideia, e como um espelho, apenas reflete emsi aquilo que a Ideia é, isto é, Vontade. Então, faz sentido Schopenhauer dizer "não se pode mais separar quem intui da intuição, mas ambos se tornaram unos" (ibidem, p. 246). Nesta condição, estabelece-se o presente contínuo que o filósofo evoca na citação acima, visto que no momento de contemplação, por não ser regido pelo tempo, como não há hora para acabar, pode durar segundos ou "até ao extremo de conter perigo de morte" (MAIA, I99I, p. I95).

O estado estético pode ser definido como uma disposição interna ou uma ocasião externa. Por isso o conhecimento da Ideia exige uma transformação tanto no sujeito quanto no objeto. Logo em seguida desaparece por inteiro o limite entre sujeito e objeto. A passagem do conhecimento comum para o estado estético é súbita e espontânea. Por esta razão, Schopenhauer diz que o objeto em questão se transforma de imediato na Ideia e o indivíduo em puro sujeito do conhecimento, havendo, neste instante, uma supressão da individualidade.

O que o puro sujeito do conhecimento contempla é representação sem a luz do princípio de razão, porque a Ideia dispõe da forma mais geral da 
representação: ser objeto para um sujeito. Assim, ao contemplar a Ideia, o puro sujeito contempla a cópia da Vontade.

O conhecimento da Ideia é uma espécie de contemplação que apenas considera o que há de essência no objeto, algo estranho a qualquer relação que lembre o princípio de razão. Um conhecimento intuitivo, em função de que o objeto contemplado estabelece uma relação de identidade com a Ideia.

É importante destacar que o indivíduo, para obter conhecimento de algo, faz uso de dois tipos de intuição: a empírica e a estética. A empírica está submetida ao princípio de razão, e é por meio dela que se descobre o corpo como vontade e os demais objetos da realidade fenomênica. A intuição estética, por sua vez, é livre das formas do princípio razão. É pela intuição estética que se dá o encontro entre o indivíduo e a Ideia, visto que a Ideia, encontrandose numa condição atemporal, poderá ser intuída por meio da contemplação desinteressada do belo. Quando o sujeito do conhecimento contempla a obra de arte ou a própria natureza, há um "salto" do conhecimento submetido ao princípio de razão para o conhecimento da Ideia:

Este "salto" no conhecimento significaria, acaso, um ocupar-se com a transcendência? A resposta é, sem dúvida, um não; pois, o sabemos, a metafísica de Schopenhauer é de caráter empírico. Não há, neste universo filosófico, a pretensão de atingir a transcendência, e nisto Schopenhauer mantém-se firmemente apoiado em Kant. Ainda que a metafísica schopenhaueriana ultrapasse o aparecer e alcance a essência do mundo, o faz a partir da natureza, para desvelar o que "nela ou atrás dela se oculta (...) considerando-o, porém, sempre apenas enquanto isto que nela aparece, não entretanto, independentemente de todo o aparecimento" (MAIA: I99I, p. I43).

A saída schopenhaueriana para o conhecimento da Coisa-Em-Si é um dogma. Entretanto, este dogma é imanente. O conhecimento ou sentimento da Ideia acontece por meio da experiência, porque a natureza é a manifestação fenomênica da Vontade. A vontade individual junto à representação da CoisaEm-Si é anulada. Por isso, também a elevação do intelecto, restando, assim, uma única e mesma essência. Esta é a principal característica da experiência estética.

A Coisa-Em-Si kantiana torna-se cognoscível por meio da representação imanente. Por meio de um conhecimento primeiramente transcendental, chegase ao conhecimento da Ideia. Desfaz-se de todas as formas de conhecimento e permanece somente uma: a de ser objeto para um sujeito, forma mais geral da representação. Discípulo fiel de Kant, Schopenhauer continua fiel ao mestre, como comenta Jair Barboza:

As Ideias são as objetidades mais adequadas possíveis da Vontade como coisa-em-si, e, assim, não é o em-si originalíssimo que se dá a intuição estético-transcendental, mas 
sua tradução fidelíssima. A Ideia, apesar de sua cristalinidade, imutabilidade e verdade superior face ao fenômeno, continua uma representação na consciência a guardar a forma a mais geral dos seus conteúdos, o ser-objeto para um sujeito; já a Vontade disto se isenta (BARBOZA, 200I, p. 58-59).

O que é conhecido é somente a Ideia, a Coisa-Em-Si ainda permanece mistério para o sujeito e para a teoria do conhecimento de Schopenhauer. O fundamento metafísico do mundo é apresentado e consolidado pelo filósofo por meio do conhecimento intuitivo da Ideia, por isso a contemplação estética é denominada por ele de "intuição pura". É pela contemplação que o querer é suprimido e o véu da ilusão que cobria os olhos do indivíduo é retirado, tornando, assim, possível, um verdadeiro conhecimento. O caminho apresentado pelo autor de $O$ mundo... é a contemplação desinteressada da obra de arte em suas diversas ramificações ou a contemplação desinteressada da natureza. A contemplação, mesmo que momentânea, é o que permite ao sujeito negar a sua vontade individual e conhecer a Ideia.

\section{Referências Bibliográficas}

ABBGANANO, Nicola. Dicionário de Filosofia. Tradução da I. ${ }^{a}$ edição brasileira coordenada e revista por Alfredo Bosi; revisão da tradução e tradução dos novos textos. Ivone Castilho Benedetti. 5. ${ }^{\mathrm{a}}$ ed.- São Paulo: Martins Fontes, 2007.

BARBOZA, Jair. A metafísica do belo de Arthur Schopenhauer. São Paulo: Humanitas/ FFLGH/ USP, $200 \mathrm{I}$.

KANT, Immanuel. Textos Seletos - prefácio à segunda edição da Crítica da Razão Pura. Tradução de Raimundo Vier. 3. ${ }^{\mathrm{a}}$ ed. Petrópolis, RJ: Vozes, 2005.

MAIA, Muriel. A outra face do nada. São Paulo, Vozes, I99I.

SGHOPENHAUER, Arthur. O mundo como vontade e como representação. Tradução, apresentação, notas e índices de Jair Barboza. São Paulo: Editora UNESP, 2005 .

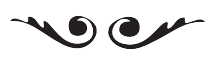

Sara Pereira Dias é graduanda em Filosofia pela UNIMONTES.

E-mail:saradiasmoc@yahoo.com.br 